Assiut Scientific Nursing Journal

http://asnj.journals.ekb.eg

http://www.arabimpactfactor.com

\title{
Effect of Behavioral Intervention Program on Quality of Life of Urinary Incontinence Elderly Patients at Assiut University Hospital
}

\author{
Hanaa Moukhtar Ibrahim ${ }^{1}$, Walaa Hassan Abd El Fatah ${ }^{2}$, Hawidaa Khalaf Abd_Elaal ${ }^{3}$, Karima Mohamed \\ Sobhy ${ }^{4}$. \\ 1. Gerontological Nursing, Faculty of Nursing, Assuit University, Egypt. \\ 2. Community Health Nursing, Faculty of Nursing, Assuit University, Egypt. \\ 3. Phd, Medical Surgical Nursing Center of Technical Training and Nursing Development for Assiut University \\ hospitals, Faculty of Nursing, Egypt. \\ 4. Public Health and Community Medicine, Faculty of Medicine, Assuit University, Hospital, Egypt.
}

\begin{abstract}
Urinary incontinence is considered a stigmatizing condition in most populations, especially elderly people which contributes to poor quality of life. Aim: Assess quality of life among elderly suffering from urinary incontinence and evaluate the effect of behavioral intervention on Quality of Life of urinary incontinence elderly patients. Subject and method: A quasi-experimental pre and post-test design was utilized. It involved 73 elderly participants selected by simple random sample from outpatient clinics in urology and general hospital at Assiut University Hospitals. Three tools were utilized. $1^{\text {st }}$ tool: An interview questionnaire sheet for collection of demographic data, medical and urology history, $2^{\text {nd }}$ tool: Questionnaire for Urinary Incontinence Diagnosis (QUID). $3^{\text {rd }}$ tool; International Consultation on Incontinence Questionnaire Short Form (ICIQ-SF). Studied participants were evaluated at baseline and after three months of program. Results: A statistically significant $\mathbf{P = 0 . 0 0 1}$ was found between pre and post-test among elderly in terms of mean scores obtained from QOL domain of the ICIQ-SF was $9.49 \pm 1.48$ and $5.9 \pm 2.1$, respectively. Conclusions: Behavioral intervention program are effective in reducing severity of urinary incontinence. Given the study results, it is recommended that expand of public education efforts through various channels about importance of behavioral intervention for appropriate management of urinary incontinence among elderly.
\end{abstract}

\section{Keywords: Behavioral Intervention, Elderly \& Urinary Incontinence.}

\section{Introduction}

Elderly people denote a population group that requires a specific and integral approach that promotes their wellbeing and health. There are contextual factors experiences during this life stage, such as the generation of diseases, which can influence negatively central aspects of life (LeónNavarrete et al., 2017)

As population aging rises in both developed and developing countries, Egypt like many other countries is undergoing a demographic transition toward an aging society. There were 4400000 persons aged 60 years and over, representing $6.9 \%$ of the total population in 2006, whereas the expected percentage of elderly population may reach $8.9 \%$ in 2016 and $10.9 \%$ in 2026, and finally $12 \%$ by 2030 (Shaheen et al., 2017).

Urologic issues are the third most common type of complaints in patients aged $65 \mathrm{yr}$. or older, accounting for at least $47 \%$ of office visits. One of the most predominant urologic problems among the elderly is urinary incontinence (UI) (Dyche \& Hollander, 2009). Also; the number of people with UI is expected to increase, because UI prevalence increases with advancing age (Knorst et al., 2011, \& Sung et al., 2012).

UI can be defined as the involuntary leakage of urine resulting from the inability to reach the toilet due to cognitive, functional, or mobility impairments in the presence of an intact lower urinary tract system (Abrams et al., 2013). Moreover, it is an undeniable psychosocial problem creating embarrassment, negative self-perception, and has a severe impact on a patient's quality of life (Özdemir \& Surmeli, 2017). Quality of Life (QOL) is a multidimensional concept which incorporates the social, physical and mental aspects of the individual. Even if; incontinence is not a life-threatening disease, but it can have multiple effects on daily activities, social interactions and the perception of health. It leads to reduce quality of life, to cause social isolation and restriction life styles (Leroy, \& Lopes, 2012).

Therefore, this disease, as a social problem, personal health prevents employment and education leads to shame and causes rejection from society, ultimately it resulted in moving older peoples from family home to nursing home (Basak, et al., 2012, Mladenović, et al., 2011 \& Riss, \& Kargl, 2011) 
Physiological changes with ageing mean that all types of UI become more common with increasing age (Burkhard et al., 2018). In addition to; several chronic diseases (as diabetes mellitus, Parkinson's disease, dementia, stroke, prostatic cancer, chronic obstructive pulmonary disease (COPD) and arthritis) and environmental factors include inaccessible or unsafe toilet facilities and the absence of caregivers for toileting assistance increase the risk of urinary incontinence in elderly (WHO, 2017).

Today, there are wide different treatment options in urinary incontinence from surgery to conservative modalities. Conservative management approaches are recommended as the first-line for UI management, but it differs according to the underlying pathophysiological mechanism, defining subtypes of UI and severity of symptoms (Özdemir \& Surmeli, 2017).

Behavioral interventions are a group of interventions that improve UI and other lower urinary tract symptoms by changing patient's daily habits or teaching new skills. One basic approach to behavioral treatment focuses on improving bladder control by modifying voiding habits, as scheduled voiding or delayed voiding. Another approach focuses on the bladder outlet, strengthening pelvic floor muscles and using them to prevent leakage and control bladder function (Wagg et al., 2015).

Heath care provider should maintain contact with the elderly patients during the period of time when benefit is not yet appreciable. It is essential that clinicians support the patient's ongoing efforts by scheduling follow-up appointments to review and reinforce their progress, assess adherence, encourage persistence, identify and address barriers, and make any needed adjustments to daily regimen (Burgio, 2014).

Definitely, nurses are ideally placed to perform the initial assessment, establish appropriate management of incontinence and provide valuable education to empower patients, that portion of the care pathway which is crucial, but often poorly done (Peplar \& Wragg, 2010).

\section{Significance of the Study}

Urinary incontinence (UI) is an enormously common complaint in every part of the world. It causes a great deal of distress and embarrassment to both individuals and societies. However, there is universal agreement about the significance of the problem in terms of human suffering and economic cost (Lucas et al., 2017).

Variety of studies in Egypt documented the overall prevalence of UI among the elderly population as; (Elserafy et al., 2019 \& El-Azab et al., 2007) which were pointed out the prevalence of UI was $67 \%$. In addition; urinary incontinence affects about $30 \%$ of elderly people living in the community, between $40 \%$ and $70 \%$ of hospitalized elderly and $50 \%$ of elderly living in long-term care facilities (Haylen et al., 2010).

Aims of the study

1. To assess quality of life among elderly people suffering from urinary incontinence.

2. To evaluate the effect of behavioral intervention on Quality of Life of urinary incontinence elderly patients

\section{Research hypotheses}

Hypotheses: Behavioral Intervention will reduce the severity of UI among elderly Patients.

Null Hypotheses: Behavioral Intervention will not reduce the severity of UI among elderly Patients.

\section{Subjects and Methods}

Study design:

A quasi-experimental design with a pre and posttest group was used.

\section{Study's setting}

This study was conducted in outpatients' clinics of urology and general hospital at Assiut University Hospitals which include (urology, diabetic, and internal medicine outpatient clinics).

\section{Sample size:}

The present study includes a simple random sample of 73 elderly participants aged 60 years and more who suffering from urinary incontinence. Each of them with any of the following conditions was excluded: elderly having lower urinary tract stone, prostatic hyperplasia, mobility problems and those taking medications for urinary continence. These factors are known to increase the incidence and severity of UI, therefore could be the extraneous variables for intervention effects.

Tools of the study: three tools were used to evaluate elderly throughout program phases in the present study

The $1^{\text {st }}$ tool: A structured interviewing questionnaire which consisted of 2 main parts:

Part I. Socio-demographic data: age, gender, marital status, residence, educational level, and occupation.

Part II. Medical and Urology history: as; Hypertension, DM, cardiovascular disease history, stone formation either renal or bladder, Urinary tract infection, Burning with urination, weak stream.

The $2^{\text {nd }}$ tool: The Questionnaire for Urinary Incontinence Diagnosis (QUID):

It is a 6-items urinary incontinence (UI) symptoms questionnaire, were used to distinguish stress and urge UI. These included 3 items about stress urinary incontinence and 3 items about urge urinary incontinence. Each item scores ranged from 0 to 5 . Responses to items 1, 2 and 3 are summed for Stress 
score; and responses to items 4, 5, and 6 are summed for Urge score. Use of QUID scores (Stress UI scores $\geq 4$ and Urge UI scores $\geq 6$ ) (Bradley et al., 2010).

This questionnaire was measured two times throughout the study on each patient, first time at starting of the intervention and the second time, was after three months from intervention.

Validity and Reliability of the tool

This scale widely used valid and reliable tool by Bradley et al., 2010. Also; the Arabic version of QUID appears to be a reliable and valid instrument with high internal consistency with a Pearson correlation coefficient of .87 by Elserafya et al., 2019 among elderly women in Egypt.

The $3^{\text {rd }}$ tool: International Consultation on Incontinence Questionnaire Short Form (ICIQSF)

It is a brief assessment tool provided insight for measuring the symptoms and impact of urinary incontinence (UI) on quality of life (QOL) and information on situations in which incontinence occurred. The ICIQ-UI-SF score is divided into four severity levels. Firstly; the questionnaire score with the QOL dimension include: slight (1-5), moderate (6-12), severe (13-18) and very severe (19-21). While the score without a QOL dimension ranged into: slight (1-3), moderate (4-5), severe (6-9) and very severe (10-11) (Klovning et al., 2009).

This questionnaire was measured two times throughout the study on each patient, first time at starting of the intervention and the second time was after three months. It is a reliable and valid tool for UI assessment (Hajebrahimi et al., 2011). Also; the Arabic version of it appears to be a reliable and valid according to: Hashim et al., 2006 \& Soliman et al., 2017 in Egypt.

\section{Pilot Study}

A pilot study was applied on 10 of the elderly patients which were included in the total study sample because there weren't any modifications in the form.

\section{Ethical considerations}

Research proposal was accepted from Ethical Committee of Nursing Faculty at Assiut University. There was no dangerous for study participants during application of behavioral intervention. The study was following common ethical principles in clinical research. Also, written consent was taken from each participant after explaining the nature and purpose of the study. Confidentiality and anonymity were assured. Every studied patient has ethical rights to agree or refuse to participate in the study. Study subject privacy was considered during data collection. Field Work

An official approval letter was obtained from the Dean of nursing faculty and director of Assiut
University Hospital, which include a permission to carry out the study. Data was collected through a period from beginning of February 2018 to the end of May 2019, two days/week; include $2-3$ participants / day, from 9.00 a.m. to 2.00 p.m.

\section{Baseline assessment}

Firstly, the researchers introduced themselves to the participants and explain the study purpose, after that Pre-test was done to evaluate the participants' symptoms and impact of urinary incontinence (UI) on quality of life (QOL) through using the previous study tools (1. 2and3).

Intervention: it include applying behavioral intervention program

According to the study criteria, the selected participants were attending two sessions every week for three months. Each session includes 2-3 elderly patients and took approximately 50 minutes.

- At the beginning of session, the researchers distributed simple pictures and handouts. then; the researchers took half an hour in urinary incontinence education include definition, causes, risk factors, types, symptoms, diagnoses, herbal treatment and behavioral intervention which composed of performing pelvic floor muscles (PFM) exercise combined with bladder training.

- At the end of each educational session, the researchers spent 20 minutes to accomplish deepest exercise compliance in instruction each patient in the intervention to perform PFM exercises (Kegel exercise) five times daily at home during micturition, sitting and standing. These exercises strengthen urinary sphincter and pelvic floor muscles. It involves repeatedly tightening, holding, and then relaxing the pelvic muscles. Also; in description of bladder training which means emptying of bladder at regular intervals. The schedule should be based on the individual's urinary elimination patterns, begin by scheduling toileting at $2 \mathrm{hrs}$. intervals.

Evaluation stage

In this stage the post-test was completed after three months using International Consultation on Incontinence Questionnaire Short Form (ICIQSF) to assess urinary incontinence symptoms and its impact on QOL. The interview and program application were carried out in the health education room of diabetic and outpatient clinics of urology, hypertension, and internal medicine.

\section{Statistical analysis}

All analysis were done using SPSS version 20. The data were tested for normality using AndersonDarling test and for homogeneity variances prior to 
further statistical analysis. Categorical variables were described by number and percent $(\mathrm{N}, \%)$, where continuous variables described by mean and standard deviation (Mean, SD). While; comparison between continuous variables by t-test and ANOVA test. A two-tailed $\mathrm{p}<0.05$ was considered statistically significant. Pearson Correlation was used to appear the association between scores.

\section{Result}

Table (1): Distribution of studied elderly according to their socio-demographic characteristics in Assiut University hospital's outpatients' clinics $(n=73)$

\begin{tabular}{|c|c|c|}
\hline & No & $\%$ \\
\hline \multicolumn{3}{|l|}{ - $\quad$ Age group } \\
\hline $60-74$ years & 46 & 63.0 \\
\hline $75-84$ years & 16 & 21.9 \\
\hline 85 and more & 11 & 15.1 \\
\hline Mean +SD & \multicolumn{2}{|c|}{$73.18+14.52$} \\
\hline \multicolumn{3}{|l|}{ Gender } \\
\hline Male & 26 & 35.6 \\
\hline Female & 47 & 64.4 \\
\hline \multicolumn{3}{|l|}{ Residence } \\
\hline Rural & 37 & 50.7 \\
\hline Urban & 36 & 49.3 \\
\hline \multicolumn{3}{|l|}{ Education } \\
\hline Illiterate & 19 & 26.0 \\
\hline primary education & 9 & 12.3 \\
\hline Preparatory education & 10 & 13.7 \\
\hline Secondary education & 12 & 16.4 \\
\hline University & 23 & 31.5 \\
\hline \multicolumn{3}{|l|}{ Marital Status } \\
\hline Married & 53 & 72.6 \\
\hline Widow & 17 & 23.3 \\
\hline Divorced & 3 & 4.1 \\
\hline \multicolumn{3}{|l|}{ Occupation } \\
\hline Not working & 14 & 19.2 \\
\hline Farmer & 10 & 13.7 \\
\hline Housewife & 21 & 28.8 \\
\hline Retired & 16 & 21.9 \\
\hline Skills & 12 & 16.4 \\
\hline \multicolumn{3}{|l|}{ - $\quad$ Medical history } \\
\hline No Complain & 12 & 16.4 \\
\hline Diabetes & 23 & 31.5 \\
\hline heart diseases & 2 & 2.7 \\
\hline More than Complain & 36 & 49.3 \\
\hline \multicolumn{3}{|l|}{ - $\quad$ Urology history } \\
\hline Stone formation & 13 & 17.8 \\
\hline Urinary tract infection & 18 & 24.7 \\
\hline Prostate enlargement & 9 & 12.3 \\
\hline Poly urea & 8 & 11.0 \\
\hline Burning with urination & 12 & 16.4 \\
\hline weak stream & 1 & 1.4 \\
\hline more than one problem & 12 & 16.4 \\
\hline
\end{tabular}




\section{Urinary Incontinence Diagnosis}

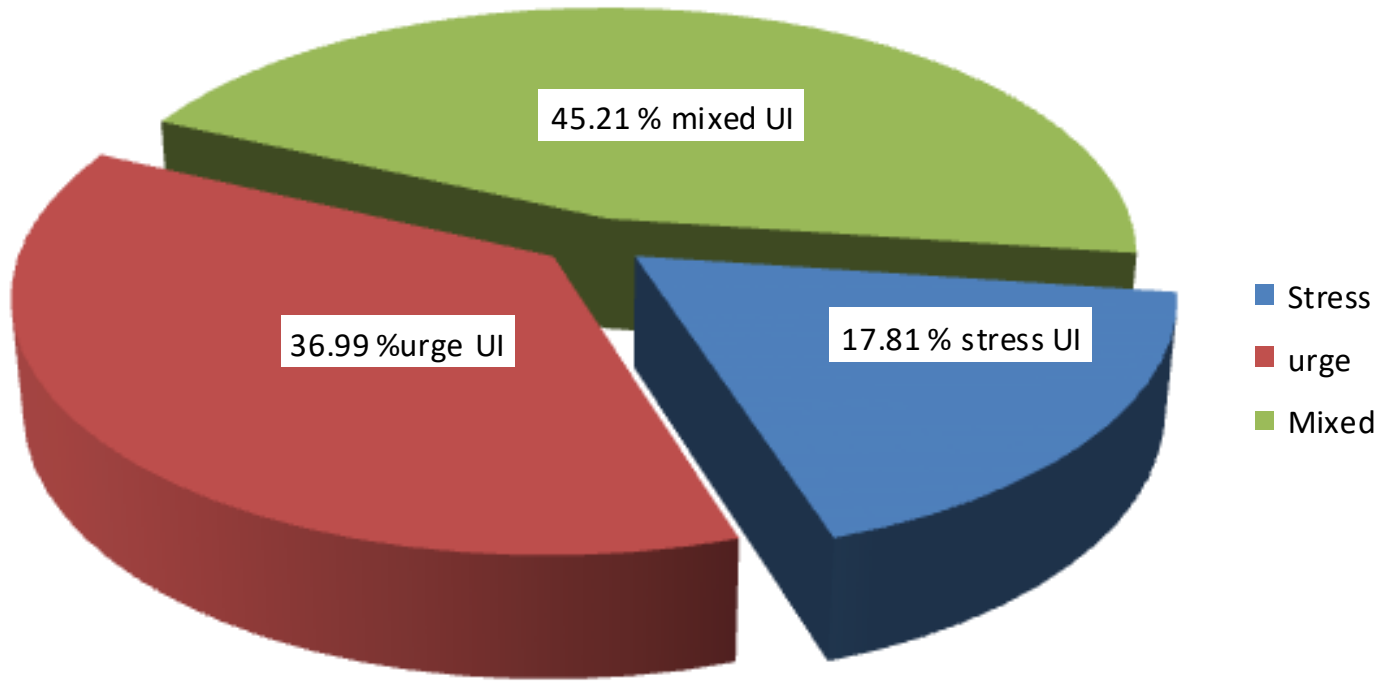

Figure (1): Illustrates types of urinary incontinence among studied participants according to Questionnaire for Urinary Incontinence Diagnosis (QUID), (n=73)

Table (2): Impact of urinary incontinence (UI) on elderly participants quality of life (QOL) based on International Consultation on Incontinence Questionnaire Short Form (ICIQ-UI SF) Before and After education Program $(n=73)$

\begin{tabular}{|c|c|c|c|c|c|}
\hline \multirow{2}{*}{ ICIQ-UI Short Form Domains } & \multicolumn{2}{|c|}{ Pre-test } & \multicolumn{2}{|c|}{ Post-test } & \multirow[t]{2}{*}{ P.value } \\
\hline & No & $\%$ & No & $\%$ & \\
\hline \multicolumn{6}{|l|}{ i. Without QQL Domain } \\
\hline Slight & 5 & 6.8 & 54 & 74.0 & \multirow{4}{*}{$<0.001 * *$} \\
\hline Moderate & 27 & 37.0 & 13 & 17.8 & \\
\hline Severe & 33 & 45.2 & 3 & 4.1 & \\
\hline Very severe & 8 & 11.0 & 3 & 4.1 & \\
\hline Mean \pm SD & \multicolumn{2}{|c|}{$6.03 \pm 2.17$} & \multicolumn{2}{|c|}{$2.9 \pm 2.1$} & $<0.001 * *$ \\
\hline \multicolumn{6}{|l|}{ ii. With QQL Domain } \\
\hline Slight & 1 & 1.4 & 16 & 21.9 & \multirow{4}{*}{$<0.001 * *$} \\
\hline Moderate & 8 & 11.0 & 47 & 64.4 & \\
\hline Severe & 56 & 76.7 & 7 & 9.6 & \\
\hline Very severe & 8 & 11.0 & 3 & 4.1 & \\
\hline Mean \pm SD & \multicolumn{2}{|c|}{$15.52 \pm 2.95$} & \multicolumn{2}{|c|}{$8.81 \pm 3.77$} & $<0.001 * *$ \\
\hline
\end{tabular}


Table (3): Relationship between The Questionnaire for Urinary Incontinence Diagnosis (QUID), and ICIQ-SF with/without QQL Before and After education Program (n=73).

\begin{tabular}{|c|c|c|c|c|c|}
\hline & \multirow{3}{*}{ No. } & \multicolumn{2}{|c|}{ Without QQL Domain } & \multicolumn{2}{|c|}{ With QQL Domain } \\
\hline & & Pre-test & Post-test & Pre-test & Post-test \\
\hline & & Mean \pm SD & Mean \pm SD & Mean \pm SD & Mean \pm SD \\
\hline \multicolumn{6}{|c|}{ Urinary Incontinence Diagnosis } \\
\hline Stress & 13 & $2.08 \pm 0.95$ & $1.31 \pm 0.48$ & $13.85 \pm 3.29$ & $7.62 \pm 3.31$ \\
\hline Urge & 27 & $2.44 \pm 0.51$ & $1.26 \pm 0.53$ & $14.85 \pm 2.93$ & $8.44 \pm 3.36$ \\
\hline Mixed & 33 & $2.94 \pm 0.75$ & $1.52 \pm 0.97$ & $16.73 \pm 2.36$ & $9.58 \pm 4.17$ \\
\hline P.value & & 0.062 & 0.325 & $0.009 * *$ & 0.458 \\
\hline
\end{tabular}

Kruskal-Wallis $H * *$ statistically significant difference ( $p<0.0 .01)$.

Table (4): Correlation Co- efficient between Urinary Incontinence Diagnosis ICIQ Short Form with/without QQL Before and after education Program $(n=73)$

\begin{tabular}{|l|c|c|c|c|}
\hline \multirow{2}{*}{} & \multicolumn{3}{|c|}{ Urinary Incontinence Diagnosis } \\
\cline { 2 - 5 } & \multicolumn{3}{|c|}{ Pre-test } & \multicolumn{2}{|c|}{ Post-test } \\
\cline { 2 - 5 } & $\mathrm{R}$ & $\mathrm{P}$ & $\mathrm{P}$ & 0.167 \\
\hline Without QQL & 0.277 & $0.018^{*}$ & 0.158 \\
\hline With QQL & 0.362 & $0.002^{* *}$ & 0.147 & 0.214 \\
\hline
\end{tabular}

* Statistically Significant correlation At P. value $<0.05$

** Statistically Significant correlation At P. value $<0.01$ 
Table (5): Relationship between International Consultation on Incontinence Questionnaire Short Form (ICIQ-SF) With Socio demographic data of elderly participants $(\mathbf{n}=73)$

\begin{tabular}{|c|c|c|c|c|c|}
\hline \multirow{3}{*}{ Socio demographic } & \multirow{3}{*}{ No. } & \multicolumn{2}{|c|}{ without QQL } & \multicolumn{2}{|c|}{ with QQL } \\
\hline & & Before & After & Before & After \\
\hline & & Mean \pm SD & Mean \pm SD & Mean \pm SD & Mean \pm SD \\
\hline \multicolumn{6}{|l|}{ Age group } \\
\hline from 60 - 74 years & 46 & $5.61 \pm 1.81$ & $2.43 \pm 1.66$ & $15.17 \pm 2.3$ & $7.93 \pm 3.07$ \\
\hline from $75-84$ years & 16 & $6.19 \pm 2.48$ & $3.31 \pm 2.52$ & $15.31 \pm 4.08$ & $9.44 \pm 4.87$ \\
\hline from 85 and more & 11 & $7.55 \pm 2.54$ & $4.27 \pm 2.57$ & $17.27 \pm 3.17$ & $11.55 \pm 3.42$ \\
\hline P.value & & 0.060 & 0.055 & $0.038^{*}$ & $0.006 * *$ \\
\hline \multicolumn{6}{|l|}{ Gender } \\
\hline Male & 26 & $6.81 \pm 2.14$ & $3.46 \pm 2.69$ & $16.69 \pm 2.26$ & $9.73 \pm 4.35$ \\
\hline Female & 47 & $5.6 \pm 2.08$ & $2.6 \pm 1.65$ & $14.87 \pm 3.11$ & $8.3 \pm 3.34$ \\
\hline P.value & & $0.023^{*}$ & $0.017 *$ & 0.202 & 0.199 \\
\hline \multicolumn{6}{|l|}{ Residence } \\
\hline Rural & 37 & $6.05 \pm 1.76$ & $2.95 \pm 1.47$ & $15.3 \pm 3.08$ & $8.84 \pm 3.35$ \\
\hline Urban & 36 & $6 \pm 2.54$ & $2.86 \pm 2.62$ & $15.75 \pm 2.84$ & $8.78 \pm 4.2$ \\
\hline P.value & & 0.553 & 0.929 & 0.158 & 0.467 \\
\hline \multicolumn{6}{|l|}{ Education } \\
\hline Illiterate & 19 & $6.89 \pm 2.05$ & $3.47 \pm 1.58$ & $16.47 \pm 2.74$ & $9.68 \pm 3.04$ \\
\hline primiary education & 9 & $5.22 \pm 1.72$ & $2.11 \pm 1.17$ & $14.89 \pm 2.37$ & $8.11 \pm 2.52$ \\
\hline Preparatory education & 10 & $6.7 \pm 2.36$ & $3.8 \pm 2.39$ & $16.3 \pm 2.95$ & $10.5 \pm 4.48$ \\
\hline Secondary education & 12 & $6.42 \pm 2.19$ & $3.25 \pm 2.45$ & $15.5 \pm 4.19$ & $8.83 \pm 4.75$ \\
\hline University & 23 & $5.13 \pm 2.03$ & $2.17 \pm 2.25$ & $14.65 \pm 2.46$ & $7.61 \pm 3.66$ \\
\hline P.value & & $0.026^{*}$ & 0.081 & $0.005 * *$ & 0.145 \\
\hline \multicolumn{6}{|l|}{ marital Status } \\
\hline Married & 53 & $5.98 \pm 2.16$ & $2.81 \pm 2.04$ & $15.57 \pm 2.73$ & $8.55 \pm 3.38$ \\
\hline Widow & 17 & $6 \pm 2.03$ & $3.47 \pm 2.35$ & $15.29 \pm 3.55$ & $10.18 \pm 4.64$ \\
\hline Divorced & 3 & $7 \pm 3.61$ & $1.33 \pm 0.58$ & $16 \pm 4.36$ & $5.67 \pm 3.06$ \\
\hline P.value & & 0.871 & 0.971 & 0.132 & 0.083 \\
\hline \multicolumn{6}{|l|}{ - $\quad$ Occupation } \\
\hline Not working & 14 & $7.14 \pm 1.96$ & $3.71 \pm 2.27$ & $16.79 \pm 2.64$ & $9.71 \pm 3.89$ \\
\hline Farmer & 10 & $6.2 \pm 1.99$ & $3.5 \pm 2.55$ & $16.1 \pm 2.02$ & $10.7 \pm 3.95$ \\
\hline Housewife & 21 & $5.43 \pm 2.09$ & $2.62 \pm 1.6$ & $14.43 \pm 3.59$ & $8.43 \pm 3.88$ \\
\hline Retired & 16 & $6.69 \pm 2.57$ & $3.13 \pm 2.58$ & $16.06 \pm 3.34$ & $9 \pm 3.93$ \\
\hline Skills & 12 & $4.75 \pm 1.14$ & $1.67 \pm 0.89$ & $14.75 \pm 1.14$ & $6.58 \pm 1.93$ \\
\hline P.value & & $0.022 *$ & 0.067 & 0.056 & 0.057 \\
\hline \multicolumn{6}{|l|}{ - $\quad$ Medical history } \\
\hline No Complain & 12 & $4.67 \pm 1.5$ & $1.5 \pm 1$ & $14.67 \pm 1.5$ & $6.5 \pm 1.93$ \\
\hline Diabetes & 23 & $5.7 \pm 1.82$ & $2.26 \pm 1.21$ & $15.3 \pm 2.44$ & $7.91 \pm 2.64$ \\
\hline Heart diseases & 2 & $10.5 \pm 0.71$ & $4 \pm 2.83$ & $20.5 \pm 0.71$ & $11.5 \pm 3.54$ \\
\hline More than Complained & 36 & $6.44 \pm 2.2$ & $3.72 \pm 2.43$ & $15.67 \pm 3.43$ & $10 \pm 4.36$ \\
\hline P.value & & $0.008 * *$ & $0.049 *$ & $0.002 * *$ & $0.010^{*}$ \\
\hline \multicolumn{6}{|l|}{$\begin{array}{ll} & \text { Urology history }\end{array}$} \\
\hline Stone formation & 13 & $6.23 \pm 2.31$ & $3.38 \pm 3.1$ & $16 \pm 2.77$ & $10.69 \pm 4.37$ \\
\hline Urinary tract infection & 18 & $5.17 \pm 1.82$ & $2.39 \pm 1.61$ & $14.22 \pm 3.52$ & $7.72 \pm 3.46$ \\
\hline Prostatic enlargement & 9 & $6.78 \pm 1.92$ & $2.89 \pm 1.17$ & $16.78 \pm 1.92$ & $8.44 \pm 2.24$ \\
\hline Poly urea & 8 & $5.63 \pm 2.26$ & $2.63 \pm 1.92$ & $14.75 \pm 2.96$ & $8.13 \pm 3.27$ \\
\hline Burning with urination & 12 & $5.75 \pm 1.96$ & $3.08 \pm 1.73$ & $15.67 \pm 2.1$ & $9.33 \pm 3.82$ \\
\hline Weak stream & 1 & $8 \pm 0$ & $4 \pm 0$ & $18 \pm 0$ & $12 \pm 0$ \\
\hline More than one problem & 12 & $6.92 \pm 2.61$ & $3.08 \pm 2.68$ & $16.17 \pm 3.33$ & $8.33 \pm 4.52$ \\
\hline P. value & & 0.272 & 0.342 & 0.774 & 0.367 \\
\hline
\end{tabular}

Mann-whitney $U^{*}$ statistically significant difference ( $\left.p<0.0 .05\right)$. **statistically significant difference ( $\left.p<0.0 .01\right)$ Kruskal-wallis $H$ *statistically significant difference ( $p<0.0 .05)$. **statistically significant difference $(p<0.0 .01)$ 
Table (1): Showed socio-demographic characteristics of study participants. The total studied sample was 73 , more than three fifth $(64.4 \%)$ of them were females and the age of them ranged from 60 to 89 with mean+DS of $73.18+14.52$. According to marital status less than three quarters $72.6 \%$ of them were married, Over half $(50.7 \%)$ of the participants coming from rural areas, $31.5 \%$ of them got higher education at university, and $28.8 \%$ were housewife. Regarding medical history of studied participants, table (1) revealed that about half $(49.3 \%)$ of them had more than one chronic disease, while the urology history in the form of urinary tract infection was observed in $24.7 \%$ of them

The results in Figure (1) revealed that the commonest type of UI among participant elderly was mixed UI $(45.21 \%)$, followed by urge type $(36.99 \%)$, and stress type was found only in $17.81 \%$ of them.

Table (2): clears that there were highly statistical significant differences throughout program phases (pre and post-test) regarding both domain of ICIQ-UI Short Form among the studied sample.

Table (3): Shows that only a statistically significant relation with ICIQ-UI Short Form QQL Domain and different type of UI at the entry of the study at P.value $=0.009$, while; there was not any statistical difference among data of our subjects in accordance to ICIQ-UI Short Form without QQL at pre and posttest of education.

Table (4): clear that there was statistical significant positive correlation $\mathrm{R}=0.277$ with $\mathrm{p}$-value $<0.018$ and $\mathrm{R}=0.362$ with $\mathrm{p}$-value $<0.002$ during pre-test for both Without QQL and With QQL of ICIQ-SF domains, respectively. While, there was not significant correlation for both after three months (post test) of education.

Table (5): this table indicated that significant differences between studied elderlies age and impact of UI with QQL in pre and post-test. Also; statistically significant between elderly's education and impact of UI with/ without QQL throughout program phases.

\section{Discussion}

Urinary incontinence (UI) is considered as a distressing and debilitating condition in elderly populations. It has a significant negative impact on quality of life (Shaheen et al., 2017).

The present study showed socio-demographic characteristics of participants. The total studied sample was 73 , more than three fifth $(63.4 \%)$ of them their age ranged from 60 to 74 with mean+DS of $73.18+14.52$ and more than one fifth $(28.8 \%)$ were housewife.

In this respect, Elserafya et al., (2019) in their study of urinary incontinence among elderly women attending rural family health center in Garbea stated that the mean age for women with UI was $67.55 \pm$ 7.12 SD years. Also; this result comes in concordance with Harai et al., (2014) study in Japan, who found that the mean age for UI among women aged 6574 years old was 69.8 years.

According to marital status less than three quarters $72.6 \%$ of them were married, Over half $(50.7 \%)$ of the participants coming from rural areas, $31.5 \%$ of them got higher education at university. Regarding medical history of studied participants, revealed that about half $(49.3 \%)$ of them had more than one chronic disease, while the urology history in the form of urinary tract infection was observed in $24.7 \%$ of them. This because UI increase the risk for urinary tract infection as well as it is considers one cause of UI.

Moreover, Elserafya et al., (2019) who documented that the mean age studied group was significantly higher among the incontinence group. Also; UI was significantly more prevalent among illiterates $(88.4 \%)$ and housewives $(92.5 \%)$.

The current study revealed that the commonest type of UI among participant elderly was mixed UI $(45.21 \%)$, followed by urge type $(36.99 \%)$, and stress type was found only in $17.81 \%$ of them. These result come in line with Elserafya et al., (2019) who reported the prevalence of UI among the studied group was $67 \%$. Mixed UI $(31 \%)$ was the most prevalent type compared with stress $(27 \%)$ and urge type (9\%) among the studied group). As regards severity of UI, $55.5 \%$ of the studied .participants was categorized as suffering from moderate UI.

On the other hand; Altaweel \& Alharbi, (2012) who study Urinary Incontinence Prevalence, Risk Factors, and Impact on Health Related Quality of Life in Saudi Women reported that the prevalence of urinary incontinence according to its type was $50 \%$ stress urinary incontinence, $28 \%$ urgency urinary incontinence, and $22 \%$ mixed urinary incontinence.

This was in disagreement with the results of a study by El Azab et al., conducted among Egyptian elderly women and that of Sensoy et al., 2013 conducted among Turkish elderly women; they stated that the prevalence of UI was 70 and $67.5 \%$, respectively. However, the study by Altaweel \& Alharbi, (2012) in Saudi Arabia stated that the prevalence of UI was $80 \%$ (61-65 years) and $100 \%$ (>65 years). These results vary due to racial, environmental, socioeconomic conditions, and the cultural differences among countries.

Additionally; the current findings agree with Elserafy et al., (2019) reported that, illiterate patients and housewives were more prevalent among the incontinence group. These results have been in line with the study by Danforth et al., (2009) stated that 
the increase in educational level helps to avoid the occurrence of UI. While Lee et al., (2003) study has shown that unemployed women experienced higher rates of UI symptoms. It may be due to the effect of sedentary life which has a negative impact on women healthcare.

On the other hand, Kim \& Kwak, (2017) stated that UI was prevalent in working women compared with unemployed women and this may be related to various occupational environments such as unclean and uncomfortable workplace, feeling pressed during work.

The current study clears that there were highly statistical significant differences throughout program phases (pre and post-test) regarding domain of ICIQUI Short Form and QOL among the studied sample. This in the same line with Jahromi et al., (2014) who studied The Effect of Pelvic Muscle Exercises on Urinary Incontinency and Self-Esteem of Elderly Females With Stress Urinary Incontinency reported that based on findings in experimental and control group, before and after the treatment, a significant statistical difference was observed (The experimental group: $p=0.04$ and the control group: $p=0.01$ ).

As regards severity of UI on elderly, moderate and sever UI was $37 \%, 45.2 \%$ respectively based on Without QQL Domain this agree with Elserafy et al., (2019) reported that, $(55.5 \%)$ was the most prevalent among the participants in this study. This result was consistent with Barentsen et al., (2012) who found that most of their patients reported mixed UI (50.7\%) and a moderate severity of symptoms (48.9\%).

In the present study that only a statistically significant relation with ICIQ-UI Short Form QQL Domain and different type of UI at P.value $=0.009$, while; there was not any statistical difference among data of studied elderly in accordance to ICIQ-UI Short Form without QQL at pre and post-test of education.

The current study results noted the impact of UI on elderly participants quality of life (QOL) based on International Consultation on Incontinence Questionnaire Short Form (ICIQ-UI SF) before and after intervention were highly statistical significant differences throughout program phases (pre and posttest) among the studied sample $\mathbf{P}$ value $=<\mathbf{0 . 0 0 1} * *$. This supported that UI is considered a stigmatizing condition in most populations, which contributes to poor quality of life.

This match with a semi experimental study was done by Syed et al., (2011) in Tabriz (Iran), on 60 elderly with the aim of applying principles of the evidencebased nursing care for urinary incontinence reported that there was statistical difference on life quality before and after the treatment $(\mathrm{p}=0.001)$ and revealed that incontinence makes a significant impact on a woman's Quality of Life (QOL).

Also, Jahromi et al., (2015) utilized study on domain of the impact of urinary incontinence on quality of life and indicated a significant statistical difference between experimental and control group before and after the treatment.

In a study that was done by Ali et al., (2011) at Shahid Akbar Abady hospital with the aim of the effect of kegel exercises on urinary incontinence, who recorded that the average score of quality of life among women's suffering urinary incontinence was 53.15 before doing kegel exercises and after the treatment was 73.82 with a significant difference between both $(p=0.0001)$. Considerable changes happened in physical and spiritual dimensions of the life quality of experimental group and were associated with improvement of their social interactions.

The current findings are consistent with Goode et al., (2011) who observed that the frequencies and amount of leakage urine in experimental group were reduced after the intervention and significantly improved of urinary incontinence by behavioral interventions program.

The present study finding indicated that statistically significant differences between participating elderlies age and impact of UI with QQL in pre and post-test among them this may be related to two third of participant from the young old age (60 - 74 years) have ability to accept and interact with health knowledge. Also; statistically significant differences was observed between participating elderly's education and impact of UI with/ without QQL throughout both program phases.

\section{Conclusions}

The present study concluded that behavioral intervention includes bladder training and pelvic muscle exercises are effective in reducing severity of urinary incontinence among elderly patients.

\section{Recommendation}

Given the results of the present study, it is recommended that expand of public education efforts through various channels including education and mass media about the importance of behavioral intervention for appropriate management of urinary incontinence.

\section{References}

1. Abrams, P., Cardozo, L., Khoury, S., \& Wein, A., (Eds.). (2013): Incontinence. Retrieved from http://www.icud.info/PDFs/ INCONTINENCE\%202013. 
2. Ali, S., Kashanian, M., \& Azari, A., (2011): The effect of pelvic floor exercises on quality of life in women with stress urinary incontinence. The Bring knowledge Magazine, 15.

3. Altaweel W., \& Alharbi M., (2012): Urinary incontinence: prevalence, risk factors, and impact on health related quality of life in Saudi women. Neurourol Urodyn; 31:642-645.

4. Barentsen J., Visser E., Hofstetter H., Maris A., Dekker J., \& de Bock G., (2012); Severity, not type, is the main predictor of decreased quality of life in elderly women with urinary incontinence: a population-based study as part of a randomized controlled trial in primary care. Health Qual Life Outcomes 2012; 10:153.

5. Basak T., Uzun S., Arslan F., (2012): Incontinence features, risk factors, and quality of life in Turkish women presenting at the hospital for urinary incontinence. $J$ Wound Ostomy Continence Nurs. 2012;39:849. [PubMed] [Google Scholar]

6. Bradley C., Rahn D., Nygaard I., Barber M., Nager C., \& Kenton K., (2010): The questionnaire for urinary incontinence diagnosis (QUID): validity and responsiveness to change in women undergoing non-surgical therapies for treatment of stress predominant urinary incontinence. Neurourol Urodyn 2010; 29:727-734.

7. Burgio, K., (2014): women's med., Lifestyle and Behavioral Therapies for Urinary Incontinence, (ISSN: 1756-2228) 2014; DOI 10.3843/GLOWM.10484

8. Burkhard C., Bosch J., Cruz F., Lemack G., Nambiar A., Thiruchelvam N., \& Tubaro A., (2018): Guidelines on Urinary Incontinence in Adults, European Association of Urology Guidelines. Edn. presented at the EAU Annual Congress Copenhagen 2018. ISBN 978-94-92671-01-1. The Netherlands. http://uroweb.org/guidelines/compilations-ofall-guidelines/.

9. Danforth K., Townsend M., Curhan G., Resnick N., \& Grodstein F., (2009): Type 2 diabetes mellitus and risk of stress, urge and mixed urinary incontinence. J Urol 2009; 181:193-197.

10. Dyche D., \& Hollander J., (2009): Lower Urinary Tract Conditions in Elderly Patients. American Society of Nephrology.

11. El-Azab A., Mohamed E., Sabra H., (2007): The prevalence and risk factors of urinary incontinence and its influence on the quality of life among Egyptian women. Neurourol Urodyn 2007; 26:783-788.

12. Elserafy F., Shaheen H., Khalil N., \& Abdelrahman H., (2019): Urinary incontinence among elderly women attending a rural family health center in Gharbiya Governorate, Egypt. Menoufia Med J [serial online] 2019 [cited 2019 Dec 30];32:955-60. Available

from: http://www.mmj.eg.net/text.asp?2019/32 /3/955/268832.

13. Goode, P., Burgio, K., Kenton, K., Litman, H., \& Richter, H., (2011): Correlates and predictors of patient satisfaction with drug therapy and combined drug therapy and behavioral training for urgency urinary incontinence in women, International Urogynecol Journal, (22), 327-334.

14. Hajebrahimi S., Nourizadeh D., Hamedani R., Pezeshki M., (2011): Validity and Reliability of the International Consultation on Incontinence Questionnaire-Urinary Incontinence Short Form and Its Correlation With Urodynamic Findings, Received April 2011 Accepted January 2012.

15. Harai M., Oura A., \& Mori M., (2014): Risk factors for urinary incontinence in Japanese elderly women. Low Urin Tract Symptoms 4; 6:94-97.

16. Hashim H., Avery K., Mourad M., Chamssuddin A., Ghoniem G., Abrams P., (2006): The Arabic ICIQ-SF: an alternative language version of the English ICIQ-SF. Neurourol Urodyn;3:277-82.

17. Haylen B., Ridder D., Freeman R., Swit SE, Berghmans B., Lee J., (2010): An International Urogynecological Association (IUGA)/International Continence Society (ICS) joint report on the terminology for female pelvic $\mathrm{fl}$ oor dysfunc $\Theta$ on. Neurourol Urodyn. 2010; 29(1):4-20.

18. Jahromi M., Talebizadeh M., \& Mirzaei M., (2015): The Effect of Pelvic Muscle Exercises on Urinary Incontinency and Self-Esteem of Elderly Females With Stress Urinary Incontinency, Global Journal of Health Science; Vol. 7, No. 2; 2015 ISSN 1916-9736 E-ISSN 1916-9744.

19. Kim Y., \& Kwak Y., (2017): Urinary incontinence in women in relation to occupational status. Women Health 2017; 57:1-18.

20. Klovning, A., Avery, K., Sandvik, H., \& Hunskar, S., (2009): Comparison of Two Questionairres for Assessing th Severity of Urinary Incontinence: The ICIQ-UI SF Versus 
the Incontinence Severity Index. Neurourol Urodyn.2009, 28, 411-415. [CrossRef] [PubMed]

21. Knorst M., Resende T., \& Goldim J., (2011): Clinical profile, quality of life and depressive symptoms of women with urinary incontinence attending a 6 . university hospital. Rev Bras Fisioter. 2011 Mar-Apr;15(2):10916. Portuguese, English.

22. Lee K., Sung H., Na S., \& Choo M., (2003): Prevelance of Urinary Incontinence in Korean Women results of a National Health Interview Survey. World J Urol 2003; 26:179-185.

23. León-Navarrete, M., Flores-Villavicencio, M., Mendoza-Ruvalcaba, N., ColungaRodríguez, C., Salazar-Garza, M., SarabiaLópez, L., \& Albán-Pérez, G., (2017): Coping Strategies and Quality of Life in Elderly Population. Open Journal of Social Sciences, 5, 207-216. https://doi.org/10.4236/jss.2017.510017.

24. Leroy Lda S., Lopes M., (2012): Urinary incontinence in the puerperium and its impact on the health-related quality of life. Rev Lat Am Enfermagem. 2012; 20:34653. [PubMed] [Google Scholar]

25. Lucas M., Bedretdinova D., Berghmans L., Bosch J., Burkhard F., Cruz F., Nambiar A., Nilsson C., Tubaro A., \& Pickard R., (2017): Guidelines on Urinary Incontinence, European Association of Urology 2017 edition.

26. Mladenović Segedi L., Segedi D., Parezanović Ilić K., (2011): Quality of life in women with urinary incontinence. Med Glas Ljek komore Zenicko-doboj kantona. 2011;8:237-42. [PubMed] [Google Scholar]

27. Özdemir Ç., \& Surmeli M., (2017): Physiotherapy in Women with Urinary Incontinence, Synopsis in the Management of Urinary Incontinence, Ammar Alhasso and Holly Bekarma, IntechOpen, February 8th 2017. DOI: 10.5772/ 66704. Available from:

28. Peplar J., \& Wragg L., (2010): Development of a multidisciplinary continuing care continence assessment tool and continence care pathway. Aust N Z Contin J. 2010;16:1416, 18, 20, 22-23.

29. Riss P., Kargl J., (2011): Quality of life and urinary incontinence women. Maturitas. 2011;68:13742. [PubMed] [Google Scholar]
30. Sensoy N., Dogan N., Ozek B., Karaaslan L., (2013): Urinary incontinence in women: prevalence rates, risk factors and impact on quality of life. Pak J Med Sci 2013; 29:818-822.

31. Shaheen H., Badr S., Saleh E., (2017): Comparative study between elderly with medical problems living in endwelling houses and with families in Banha City. Menoufia Med J; 30:44.

32. Soliman T., Sherif H, Fathi A, Kandeel W, \&Abdelwahab O., (2017); Impact of transobturator vaginal tape on female stress urinary incontinence and sexual function, Arab J Urol (2017), Benha University, Benha, Egypt http://dx.doi.org/10.1016/j.aju.2017.07.002.

33. Sung W, You H, Yoon TY, Lee SJ. (2012); Socioeconomic costs of overactive bladder and stress urinary incontinence in Korea. Int Neurourol J. 2012 Mar;16(1):23-9. ${ }^{1}$

34. Syed R., Valizadeh, S., \& Haj Ebrahim, S., (2011): Application of the principles of evidence-based nursing care for urinary incontinence in elderly women. Journal of Nursing and Midwifery, Tabriz, 17, 4-11.

35. Wagg A., Gibson W., Ostaszkiewicz J., Johnson T., Markland A., (2015): Urinary incontinence in frail elderly persons: Report from the 5th International Consultation on Incontinence. Neurourol Urodyn 34: 398-406.

36. World Health Organization (WHO) Regional Office for the Western Pacific; Ageing and health: a health promotion approach for developing countries. Manila: 2003

(http://www.wpro.who.int/publications/pub_9 290610662/en/, accessed 26 July 2017). 